\title{
Impact of Background Music on the Performance of Laparoscopy Teams
}

\section{Ying Han}

Sichuan University

Bin Zheng

University of Alberta

\section{Linyong Zhao}

Sichuan University

Jiankun Hu

Sichuan University

Chao Zhang

Sichuan University

\section{Ran Xiao}

Sichuan University

\section{Chunyan Wang}

West China Academic Exchange Center of Health and Medicine, Chengdu, Sichuan Province

Dan Pu ( $\sim$ pudan8012@126.com )

Sichuan University

\section{Research Article}

Keywords: Team performance, laparoscopic surgery, acoustic distraction, video analysis, simulation, surgical training

Posted Date: November 11th, 2021

DOl: https://doi.org/10.21203/rs.3.rs-1050433/v1

License: (1) (1) This work is licensed under a Creative Commons Attribution 4.0 International License. Read Full License 


\section{Abstract}

BACKGROUND: Music and noise have different impacts on individuals in the operating room. Their effects on the performance of surgical teams in simulated environments are not well documented. We investigated if laparoscopic teams operating under favorable acoustic conditions would perform better than under noisy conditions.

METHODS: We recruited 114 surgical residents and built 57 two-person teams. Each team was required to perform two laparoscopic tasks (object transportation and collaborative suturing) on a simulation training box under musical, neutral, and noisy acoustic conditions. Data were extracted from video recordings of each performance for analysis. Task performance was measured by the duration of time to complete a task and the total number of errors, and objective performance scores. The measures were compared over the three acoustic conditions.

RESULTS: A musical environment elicited higher performance scores than a noisy environment for both the object transportation (performance score: $66.3 \pm 8.6$ vs. $57.6 \pm 11.2 ; p<0.001$ ) and collaborative suturing tasks $(78.6 \pm 5.4$ vs. $67.2 \pm 11.1 ; p<0.001)$. Task times in the musical and noisy environments was subtracted to produce a musical-noisy difference time. Pearson correlation coefficient analysis showed a significant negative relationship between the team experience score and the musical-noisy difference time on the object transportation $(r=-0.246, p=0.046)$ and collaborative suturing tasks $(r=-0.248, p=0.044)$.

CONCLUSIONS: As to individuals, music enhances the performance of a laparoscopy team while noise worsens performance. The negative correlation between team experience and musical-noisy difference time suggests that laparoscopy teams composed of experienced surgeons are less likely affected by an acoustic distraction than novice teams. Team resistance to acoustic distraction may lead to a new way for assessing team skills.

\section{Introduction}

Music is commonly allowed during surgery in many operating theatres worldwide. Surgical staff has reported that music can reduce stress and increase efficiency [1-4]. Several studies have examined the impact of background music on surgical performance [5-7]. One study showed that when surgeons were allowed to select and play recordings of their preferred music, their stress was reduced and their task performance improved compared with when they had to listen to music selected by others [8]. Another study found that music composed by Mozart evoked a relaxed mood and resulted in improved surgical performance [9] and spatial orientation ability [10].

While some claimed an improvement by playing the preferred music, others denied a positive impact or even reported a negative impact on surgical performance $[5,11,12]$. The definition of preferred music varied between different surgeons. Mozart's melody was too soporific for some, whereas Michael Jackson's music was too loud and annoying to others [11-13]. 
Surgical dexterity deteriorated in a noisy environment $[14,15]$. Negative emotions triggered by noise has led to a deterioration in the cognitive ability of surgeons due to deteriorated working memory and to interference in the decision-making process $[16,17]$. People in noisy environments reported difficulty in maintaining focus, thus showing reduced ability in assessing a situation and a tendency for selecting highrisk strategies for resolving a problem without being fully aware of the consequences $[8,18,19]$.

The impact of music on an individual is intriguing. However, the impact of music on the performance of a surgical team is complex and remains unclear [20]. Surgery is generally known as a team practice involving surgeons and other healthcare providers [21]. In addition to personal skills, the outcome of any surgical operation largely depends on the quality of team communication and collaboration [22]. In team settings, the positive impact of music may be canceled out by personal choices on their preferred music [23]. On the other hand, negative emotions triggered by unpleasant music can be 'contagious' and affect many team members, often resulting in a negative performance by the entire team [16, 24].

We report here the findings of our recent study to investigate the impact of different acoustic conditions on the performance of laparoscopic teams. We asked teams of two surgeons to perform two tasks during a simulated laparoscopic under three different background acoustic conditions: pleasant and smooth music, neutral (quiet), and noisy conditions. We hypothesized that 2-surgeon teams working under the smooth music condition would perform better than teams operating in a noisy or neutral environment. The effects would be more noticeable for teams of inexperienced surgeons than for teams of experienced surgeons since experienced surgeons might be less sensitive to an acoustic distraction as inexperienced surgeons.

\section{Methods}

\section{Study Environment}

This controlled laboratory study was conducted at the Medical Simulation Center of West China Hospital of Sichuan University. The study protocol was approved by the University of West China Hospital of Sichuan University Research Ethics Board (2019 Approval No. 1071). Informed consent was obtained from all participants prior to data collection. Each participant provided written consent before entering the study.

\section{Apparatus}

The team performance was done on a laparoscopic training box (SL-PE480, Shinno-Med Inc., Shanghai, China. Figure 1). Three $5 \mathrm{~mm}$ diameter endoscopic instruments were inserted through 3 ports to the surgical site. The surgical site was illuminated by a Stryker X8000 light source, captured by a 30-degree laparoscope, and displayed on a 26-inch high-definition monitor (CANON Legria H50FG, Tokyo, Japan). On the object transportation task, the operators used two $5 \mathrm{~mm}$ curved graspers (Ethicon Endo-Surgery Inc., Cincinnati, Ohio, USA). On the suturing task, the operator used a pair of needle drivers (ET705R, Ethicon Endo-Surgery Inc., Cincinnati, Ohio, USA) to perform the suturing and was assisted by the assistant who used a 5mm curved grasper (Ethicon Endo-Surgery Inc., Cincinnati, Ohio, USA).

\section{Participants}


A total of 114 surgical residents who had no experience of simulated laparoscopic training in teams (88 men and 26 women aged $34.3 \pm 4.8$ years) were recruited from the Department of Surgery Residency Program at the West China Hospital of Sichuan University between May 2020 and October 2020. The hospital is a leading tertiary hospital in China with specialties in minimally invasive surgery. Most participants had at least four hours of individual laparoscopic training experience with a bench-top laparoscopic training box. Some of the participants had experience performing a complete laparoscopic procedure on a virtual model. The participants were randomized into 57 two-person teams. Table 1 shows the results of a custom-designed survey of the pre-training surgical clinical experience of participants [25]. We also assessed the participants' moods before operation with the Profile of Mood States (POMS) [26] and the Positive and Negative Affect Schedule (PANAS-SF) questionnaires [27].

\section{Team Tasks}

After the surveys, two random participants arrived at the simulation lab as a team (operator and assistant) and were asked to perform two laparoscopic tasks, object transportation and collaborative suturing. For the object transportation task, the assistant was required to move the 30-degree laparoscope appropriately in order to assist the operator in transporting an object (plastic cylinder, $2 \mathrm{~cm}$ in diameter) between three pegs located at three different sides of a cardboard box $(18 \times 15 \times 9 \mathrm{~cm})$ inside the training box (Figure 1). It is essential for the assistant to understand the optical properties of the laparoscope and how to manipulate the scope to keep the object and instruments in the center of the field of view. The collaborative suturing task required the assistant to remove an obstacle (rubber band) placed on top of the surgical site so that the operator could perform a successful intracorporeal suture (Figure 1). During the task, the assistant must control the laparoscope to view the suture site, the suture needles, and the movements of a pair of needle drivers in the hands of the operator.

The two tasks included in this study address the required individual and team skills for performing a laparoscopic surgery. At the individual level, both participants must scan the surgical site, control the laparoscopy equipment, and develop eye-hand and bimanual coordination skills. At the team level, the tasks required the two team members to develop the ability to coordinate their movements and to communicate clearly with each other.[25]

\section{Procedure}

Each 2-person team was required to perform the two tasks under three different acoustic conditions. The order of the acoustic conditions were randomized to counterbalance possible learning effect in the practice. Each team was allowed a 10-minute break between acoustic conditions to minimize individual biases. Each participant in the team was required to wear headsets that delivered the acoustic condition and canceled out ambient sounds while the participant performed the tasks.

\section{Measures}

Task performance was recorded via a digital camera connected to the laparoscopic tower. Video analysis was later performed by one experienced surgeon, who was unaware of the study purposes. This surgeon examined the videos, labeled the starting and ending points of subtasks in each video, and counted the 
errors performed by the residents in each team. These measures were then used to generate a summative task score and a total score for the performance of each team.

Table 1. Task measures, subtask times, and errors that were used for the calculation of total task scores 
Table 1

A list of time and error measures taken from two tasks and the description
Object Transportation
Collaborative Suture

\begin{tabular}{|c|c|c|c|c|}
\hline & Measure & Description & Measure & Description \\
\hline \multirow[t]{6}{*}{ Time } & Total time & $\begin{array}{l}\text { Object on to Peg C - Trial } \\
\text { start }\end{array}$ & Total time & Suture cut - Trial start \\
\hline & Time on peg $A$ & $\begin{array}{l}\text { Object on to Peg A - Trial } \\
\text { start }\end{array}$ & $\begin{array}{l}\text { Time on } \\
\text { preparation }\end{array}$ & $\begin{array}{l}\text { Needle first puncture - } \\
\text { Trial start }\end{array}$ \\
\hline & Time on peg $B$ & $\begin{array}{l}\text { Object on to Peg B - Object } \\
\text { on to Peg A }\end{array}$ & $\begin{array}{l}\text { Time on } \\
\text { suturing }\end{array}$ & $\begin{array}{l}\text { Beginning of } 1 \mathrm{st} \mathrm{knot} \\
\text { tying - Needle first } \\
\text { puncture }\end{array}$ \\
\hline & Time on peg $\mathrm{C}$ & $\begin{array}{l}\text { Object on to Peg C - Object } \\
\text { on to Peg B }\end{array}$ & Time on knot 1 & $\begin{array}{l}\text { Beginning of 2nd knot } \\
\text { tying - Beginning of } \\
1 \text { st knot tying }\end{array}$ \\
\hline & & & Time on knot 2 & $\begin{array}{l}\text { Scissor in view - } \\
\text { Beginning of } 2 \text { nd knot } \\
\text { tying }\end{array}$ \\
\hline & & & Time on cutting & $\begin{array}{l}\text { Thread cut - Scissor in } \\
\text { view }\end{array}$ \\
\hline \multirow[t]{7}{*}{ Errors } & $\begin{array}{l}\text { \# of object drop } \\
(+3 \mathrm{~s})\end{array}$ & $\begin{array}{l}\text { number of plastic triangle } \\
\text { drop during entire trial }\end{array}$ & $\begin{array}{l}\text { \# of needle } \\
\text { adjustment }\end{array}$ & $\begin{array}{l}\text { Number of needle } \\
\text { being picked up, } \\
\text { orientation } \\
\text { adjustment }\end{array}$ \\
\hline & $\begin{array}{l}\text { \# of object } \\
\text { transfer between } \\
\text { hands }(+3 \mathrm{~s})\end{array}$ & $\begin{array}{l}\text { Number of object being } \\
\text { transfer between hands of } \\
\text { the chief operator }\end{array}$ & $\begin{array}{l}\text { \# of needle } \\
\text { insert/exiting }\end{array}$ & $\begin{array}{l}\text { Number of attempts } \\
\text { of needle inserting } \\
\text { and exiting the suture } \\
\text { sides }\end{array}$ \\
\hline & $\begin{array}{l}\text { \# of incorrect } \\
\text { view }(+3 \mathrm{~s})\end{array}$ & $\begin{array}{l}\text { number of object or tips of } \\
\text { instrument out of the scope } \\
\text { view }\end{array}$ & \# of cutting & $\begin{array}{l}\text { Number of attempts } \\
\text { of cutting thread after } \\
\text { knot typing }\end{array}$ \\
\hline & $\begin{array}{l}\text { \# of horizontal } \\
\text { line twist }(+3 \mathrm{~s})\end{array}$ & $\begin{array}{l}\text { Number of times when the } \\
\text { scope view is not horizontal. }\end{array}$ & $\begin{array}{l}\text { \# of incorrect } \\
\text { view }\end{array}$ & $\begin{array}{l}\text { number of object or } \\
\text { tips of instrument out } \\
\text { of the scope view }\end{array}$ \\
\hline & $\begin{array}{l}\text { \# of instruments } \\
\text { collision }(+3 \mathrm{~s})\end{array}$ & $\begin{array}{l}\text { Number of collision between } \\
\text { scope and instruments }\end{array}$ & $\begin{array}{l}\text { \# of horizontal } \\
\text { line twist }\end{array}$ & $\begin{array}{l}\text { Number of times } \\
\text { when the scope view } \\
\text { is not horizontal. }\end{array}$ \\
\hline & Communication & $\begin{array}{l}\text { Silent team }(+10 \mathrm{~s}) \text {, } \\
\text { insufficient communication } \\
(+5 \mathrm{~s})\end{array}$ & $\begin{array}{l}\text { \# of } \\
\text { instruments } \\
\text { collision }\end{array}$ & $\begin{array}{l}\text { Number of collision } \\
\text { between scope and } \\
\text { instruments }\end{array}$ \\
\hline & & & Communication & $\begin{array}{l}\text { Silent team }(+10 \mathrm{~s}) \text {, } \\
\text { insufficient } \\
\text { communication }(+5 \mathrm{~s})\end{array}$ \\
\hline
\end{tabular}


Table 1 lists the times for completing each task, subtask, and the number of errors for each of the two tasks, and provides a detailed description of each of the measures. The times of each task were calculated by subtracting the completion time with the start time of the task. A penalty (three seconds) was added to the task time for each error observed.

The recorded errors were further divided into individual and team errors. For example, dropping an object and dropping the needle when adjusting position were considered individual errors, whereas misalignment of laparoscope, collision of instruments, and miscommunications were considered as team errors. A secure knot received a zero penalty, a slipping knot received a 10-second penalty, and a knot received a 20 -second penalty, as based on Derossis' scoring system for suture quality [28].

A total score for an operation was obtained by adding the penalty times to the time taken to complete the task. To adjust the total score of each task so that it was comparable to the other task, we normalized the total score of each task to the maximum value recorded during the task, using the equations below:

\section{Normalized object transportation score $=($ Maximum - total score of trial)/Maximum $\times 100$}

\section{Normalized suturing score $=$ (Maximum - total score of teach trial)/Maximum $\times 100$}

\section{Normalized task score $=$ (Normalized object transportation score + Normalized suturing score) / 2}

The total team score was averaged by taking two team members' transportation and suturing scores.

\section{Team score $=$ (Normalized individual score $1+$ Normalized individual score 2) / 2}

The more accurately and quickly a task was completed by each team member, the higher the individual and team scores were.

\section{Post-test assessment on team quality}

At the end of each operation, the participants of each team were required to evaluate their team performance in terms of quality of interpersonal communication and cooperation. Each team member used a 10-point scale (1 the worst and 10 the best) to answer eight questions. A mean quality score was determined from the sum of the two self-rated scores from each of the two team members. 


\section{Statistical Analysis}

The study sample size (number of teams) was determined according to a similar investigation. In 2020, Yang et al. reported the effect of different emotions on laparoscopic performance. [16] They asked surgeons-in-training to perform simulated surgical tasks on the Lap Mentor (Simbionix, Tel Aviv, Israel) immediately after watching three movies that evoked different emotions. Surgeons with positive emotions performed a task within a significantly shorter time (13.7 \pm 2.5 minutes) than those with negative (18.5 \pm 3.8 minutes) and neutral emotions ( $17.7 \pm 3.9$ minutes), for approximately $35 \%$ differences between the positive-and-negative-emotion groups. We anticipated a modest $20 \%$ improvement in our study, since the impact on the performance of a surgical team might not be as strong as the impact on an individual of a team. Using a one-way analysis of variance (ANOVA) model with a two-tailed alpha of 0.05 and a beta of 0.10 (power of $90 \%$ ), we calculated a minimum of 18 teams needed in each of acoustic conditions to demonstrate significance. We eventually recruited 57 teams to test our hypothesis with SPSS Statistics 22.0 (IBM Corporate, Armonk, New York, USA). Variables such as task times and penalties were compared between the three acoustic conditions by one-way within-subject ANOVA. Post-hoc pairwise comparisons were performed by the Bonferroni method. Pearson's $r$ (correlation coefficient) was calculated to examine the correlation between the team experience score and the surgical performance score. Data were reported as means \pm standard deviations. $p<0.05$ was considered statistically significant.

\section{Results}

\section{Demographics}

This study enrolled 114 surgeons. The demographics of the participants are listed in Table 2. Most of the participants were in the early stages of laparoscopic practice, and reported a mean duration of training in laparoscopy of 2.4 years. The score of surgical experience were determined by asking each participant to report the number of the basic and advanced laparoscopic procedures that he or she had performed by the time of the study [25]. The POMS score of the participants was $103.8 \pm 3.6$, indicating that the participants were calm before the operations. The PANAS-SF scored $27.1 \pm 7.2$ and $17.0 \pm 7.0$ respectively, which confirmed that the participants felt positive before the operations. Since each participant was required to become a member of a 2-person team and undergo all three acoustic conditions in a randomized order according to the counterbalanced measures design, we did not divide them further into different experimental groups and compare their demographic characteristics. 
Table 2

Demographics of participants

\begin{tabular}{|ll|}
\hline Number of resident & $\mathbf{1 1 4}$ \\
\hline Dyad Team & 57 \\
\hline Age & $34.3 \pm 4.8$ \\
\hline Male:Female & $88: 26$ \\
\hline Years in Lap Surgical Training & $2.4 \pm 1.1$ \\
\hline Surgical Experience Score & $57.2 \pm 19.8$ \\
\hline POMS & $103.8 \pm 3.6$ \\
\hline PANAS Positive & $27.1 \pm 7.2$ \\
\hline PANAS Negative & $17.0 \pm 7.0$ \\
\hline
\end{tabular}

\section{Impact of acoustic conditions on performance}

One way within-subject ANOVA revealed significant differences on the acoustic conditions from all team performance variables, except for Penalty Operator OT and Penalty Operator OT (Table 3). The time to perform a task under the pleasant and smooth music $(65.9 \pm 17.8 \mathrm{~s})$ was shorter than the time to perform tasks in a neutral $(74.9 \pm 19.9 \mathrm{~s})$ and a noisy environment $(90.4 \pm 24.1 \mathrm{~s} ; \mathrm{P}<0.001)$. A post-hoc pairwise comparison found significant differences between the musical and noisy environments. Compared with the neutral environment, the noisy environment led to significantly more negative effects than the musical environment which led to a positive impact on performance. 
Table 3

Statistical outputs on time and error measures compared between 3 different acoustic conditions

\begin{tabular}{|c|c|c|c|c|c|c|c|c|}
\hline & & & & & p Value & p Valu & post hoc & \\
\hline & & Music & Neutral & Noise & $\begin{array}{l}\text { Auditory } \\
\text { Condition }\end{array}$ & $\begin{array}{l}\text { Music } \\
\text { vs } \\
\text { Noise }\end{array}$ & $\begin{array}{l}\text { Music } \\
\text { vs } \\
\text { Neutral }\end{array}$ & $\begin{array}{l}\text { Noise } \\
\text { vs } \\
\text { Neutral }\end{array}$ \\
\hline $\begin{array}{l}\text { Object } \\
\text { Transportation } \\
\text { (OT) }\end{array}$ & $\begin{array}{l}\text { Total OT } \\
\text { time (s) }\end{array}$ & $\begin{array}{l}65.9 \pm \\
17.8\end{array}$ & $\begin{array}{l}74.9 \pm \\
19.9\end{array}$ & $\begin{array}{l}90.4 \\
\pm \\
24.1\end{array}$ & 0 & 0 & 0.066 & 0 \\
\hline & $\begin{array}{l}\text { Subtask A } \\
\text { Time (s) }\end{array}$ & $\begin{array}{l}34.2 \pm \\
8.8\end{array}$ & $\begin{array}{l}39.6 \pm \\
12.2\end{array}$ & $\begin{array}{l}48.2 \pm \\
14.7\end{array}$ & 0 & 0 & 0.054 & 0.001 \\
\hline & $\begin{array}{l}\text { Subtask B } \\
\text { Time (s) }\end{array}$ & $\begin{array}{l}17.9 \pm \\
5.4\end{array}$ & $\begin{array}{l}20.0 \pm \\
6.0\end{array}$ & $\begin{array}{l}25.3 \\
\pm 9.3\end{array}$ & 0 & 0 & 0.342 & 0 \\
\hline & $\begin{array}{l}\text { Subtask C } \\
\text { Time (s) }\end{array}$ & $\begin{array}{l}7.8 \pm \\
3.3\end{array}$ & $\begin{array}{l}8.5 \pm \\
3.1\end{array}$ & $\begin{array}{l}9.7 \pm \\
3.4\end{array}$ & 0.006 & 0.005 & 0.784 & 0.113 \\
\hline & $\begin{array}{l}\text { Penalty } \\
\text { Operator } \\
\text { OT }\end{array}$ & $\begin{array}{l}6.3 \pm \\
0.8\end{array}$ & $\begin{array}{l}6.9 \pm \\
2.6\end{array}$ & $\begin{array}{l}6.6 \pm \\
2.1\end{array}$ & 0.329 & 0.935 & 0.411 & 0.877 \\
\hline & $\begin{array}{l}\text { Penalty } \\
\text { Team OT }\end{array}$ & $\begin{array}{l}59.2 \pm \\
23.2\end{array}$ & $\begin{array}{l}61.2 \pm \\
24.3\end{array}$ & $\begin{array}{l}68.4 \\
\pm \\
27.9\end{array}$ & 0.126 & 0.161 & 0.914 & 0.382 \\
\hline & $\begin{array}{l}\text { Total OT } \\
\text { Score }\end{array}$ & $\begin{array}{l}131.4 \pm \\
33.7\end{array}$ & $\begin{array}{l}142.9 \\
\pm 36.3\end{array}$ & $\begin{array}{l}165.4 \\
\pm \\
43.7\end{array}$ & 0 & 0 & 0.328 & 0.006 \\
\hline & $\begin{array}{l}\text { Normalized } \\
\text { OT Score }\end{array}$ & $\begin{array}{l}66.3 \pm \\
8.6\end{array}$ & $\begin{array}{l}63.4 \pm \\
9.3\end{array}$ & $\begin{array}{l}57.6 \\
\pm \\
11.2\end{array}$ & 0 & 0 & 0.324 & 0.006 \\
\hline $\begin{array}{l}\text { Collaborative } \\
\text { Suturing (CS) }\end{array}$ & $\begin{array}{l}\text { Total } \\
\text { Suture } \\
\text { Time (s) }\end{array}$ & $\begin{array}{l}165.1 \\
\pm 41.5\end{array}$ & $\begin{array}{l}210.4 \\
\pm 69.3\end{array}$ & $\begin{array}{l}262.6 \\
\pm \\
92.7\end{array}$ & 0 & 0 & 0.002 & 0 \\
\hline & $\begin{array}{l}\text { Suture } \\
\text { Preparation } \\
\text { Time (s) }\end{array}$ & $\begin{array}{l}26.5 \pm \\
9.8\end{array}$ & $\begin{array}{l}40.1 \pm \\
24.4\end{array}$ & $\begin{array}{l}62.7 \\
\pm \\
45.3\end{array}$ & 0 & 0 & 0.052 & 0 \\
\hline & $\begin{array}{l}\text { Suture } \\
\text { Needle } \\
\text { time (s) }\end{array}$ & $\begin{array}{l}23.5 \pm \\
10.7\end{array}$ & $\begin{array}{l}30.7 \pm \\
18.2\end{array}$ & $\begin{array}{l}34.5 \\
\pm \\
33.3\end{array}$ & 0.035 & 0.032 & 0.277 & 0.73 \\
\hline & $\begin{array}{l}\text { 1st Knot } \\
\text { Time (s) }\end{array}$ & $\begin{array}{l}55.9 \pm \\
25.8\end{array}$ & $\begin{array}{l}69.3 \pm \\
34.5\end{array}$ & $\begin{array}{l}87.4 \\
\pm \\
45.9\end{array}$ & 0 & 0 & 0.148 & 0.026 \\
\hline & $\begin{array}{l}\text { 2nd Knot } \\
\text { Time (s) }\end{array}$ & $\begin{array}{l}26.7 \pm \\
12.4\end{array}$ & $\begin{array}{l}35.2 \pm \\
17.8\end{array}$ & $\begin{array}{l}38.9 \\
\pm \\
21.2\end{array}$ & 0.001 & 0.001 & 0.029 & 0.784 \\
\hline
\end{tabular}




\begin{tabular}{|c|c|c|c|c|c|c|c|}
\hline \multirow[b]{2}{*}{$\begin{array}{l}\text { Cutting } \\
\text { Time (s) }\end{array}$} & \multirow[b]{2}{*}{$\begin{array}{l}24.3 \pm \\
9.7\end{array}$} & \multirow[b]{2}{*}{$\begin{array}{l}24.7 \pm \\
11.3\end{array}$} & \multirow[b]{2}{*}{$\begin{array}{l}28.9 \\
\pm \\
12.1\end{array}$} & \multirow{2}{*}{$\begin{array}{l}\text { p Value } \\
0.047\end{array}$} & \multicolumn{3}{|c|}{ p Value (post hoc) } \\
\hline & & & & & 0.046 & 0.976 & 0.127 \\
\hline $\begin{array}{l}\text { Penalty } \\
\text { Operator } \\
\text { CS }\end{array}$ & $\begin{array}{l}9.7 \pm \\
7.1\end{array}$ & $\begin{array}{l}14.6 \pm \\
9.1\end{array}$ & $\begin{array}{l}21.2 \\
\pm \\
12.4\end{array}$ & 0 & 0 & 0.025 & 0.001 \\
\hline $\begin{array}{l}\text { Penalty } \\
\text { Team CS }\end{array}$ & $\begin{array}{l}41.1 \pm \\
13.7\end{array}$ & $\begin{array}{l}44.3 \pm \\
14.7\end{array}$ & $\begin{array}{l}48.3 \\
\pm \\
17.3\end{array}$ & 0.047 & 0.042 & 0.83 & 0.495 \\
\hline $\begin{array}{l}\text { Penalty } \\
\text { Total CS }\end{array}$ & $\begin{array}{l}53.7 \pm \\
17.5\end{array}$ & $\begin{array}{l}62.1 \pm \\
20.1\end{array}$ & $\begin{array}{l}73.3 \\
\pm \\
26.4\end{array}$ & 0 & 0 & 0.128 & 0.018 \\
\hline $\begin{array}{l}\text { Total CS } \\
\text { Score }\end{array}$ & $\begin{array}{l}218.8 \\
\pm 54.8\end{array}$ & $\begin{array}{l}272.4 \\
\pm \\
84.14\end{array}$ & $\begin{array}{l}335.9 \\
\pm \\
113.6\end{array}$ & 0 & 0 & 0.004 & 0 \\
\hline $\begin{array}{l}\text { Normalized } \\
\text { Suture } \\
\text { Score }\end{array}$ & $\begin{array}{l}78.6 \pm \\
5.4\end{array}$ & $\begin{array}{l}73.4 \pm \\
8.2\end{array}$ & $\begin{array}{l}67.2 \\
\pm \\
11.1\end{array}$ & 0 & 0 & 0.004 & 0 \\
\hline
\end{tabular}

\section{Surgical experience vs. acoustic distraction}

We noticed different teams showed different degrees of resistance to an acoustic condition. We subtracted task times between a musical and noisy environment to obtain a musical-noisy difference time to describe the impact of noise on team performance as opposed to pleasant and smooth music. A large time gap between the musical and noisy environments indicated that the impact on team performance was large. The correlation between team-experience scores and the musical-noisy difference time for object transportation was $r=-0.246(p=0.046)$ and collaborative suturing $r=-0.248(p=0.044)$ tasks. As shown in Figure 2, the team with a higher score for surgical experience showed a smaller difference between the musical and noisy environments.

\section{Post-test Assessment}

At the end of each operation, team members were required to evaluate their team performance. On average, they reported $8.6 \pm 0.9$ points on a 10-point scale, a good sign for team collaboration by self-reported assessment.

\section{Discussion}

The findings of this study support our hypothesis. Laparoscopic surgical teams working in the musical environment perform significantly better than the same teams working in the noisy environment. In particular, the teams took significantly less time to complete the collaborative suturing tasks with fewer time penalties with music than noise in the background (Table 3). Exposure to a noisy environment led to a 
prolonged task time and increased the number of errors committed by both individual team members in a team. A noisy environment added cognitive loads to all team members, reducing their mental resources for processing information on the surgery, with resultant delays for decision-making and reductions in controlled movements $[14,18]$. The opposite effect was observed when operators worked in an environment with their preferred music playing. In this study, unfortunately, we did not assess the combined effects of music and noise. In future research, we will examine if music will provide a benefit to operators working in a noisy environment.

The exciting finding from this study is that collaborative teams seemed to show increased resistance to poor acoustic conditions. Surgical teams consisting of experienced surgeons displayed more resistance to change from a musical to a noisy environment than teams consisting of inexperienced surgeons. This finding suggests that collaborative teams can accommodate the negative impact of acoustic distraction and maintain their performance in those difficult and demanding environments such as in disasters and war conflicts. Our interpretation of the results regarding collaborative teams is consistent with previous studies [29-31]. Large surgical tasks become automatic in surgeons who have become skillful. The cognitive resources of skillful team members allow them to manage environmental distractions [30]. Therefore experienced team members have increased ability in dealing with extra environmental feedback while performing a task.

The negative linear relationship between team experience and impact of acoustic condition creates an opportunity for us to assess the skills of a surgical team by examining its resistance to environmental noise. This could inspire a new approach additional to the array of other assessment instruments currently used for assessing surgical team performance. Further validation is needed before we can comfortably introduce this approach for assessing team performance.

There are limitations to the current study. First, the performance videos were analyzed by one single surgeon; we may not rule off the personal bias. However, this reviewer did not know the purpose of the study and was blind to the experimental condition. Second, we were unable to report on the effect of different preferred musical stimulation provided to each of the two team members. In future research, we will make these data available for in-depth analysis. Third, the experimental setup in the study did not completely reflect the actual operating conditions. The testing tasks were relatively easy to perform. Additionally, an actual surgical procedure consists of a laparoscopic team that includes nurses, anesthesiologists, and technicians. Future research should consider to enroll entire surgical teams that perform laparoscopy as the study participants.

\section{Conclusions}

Laparoscopic teams perform better in a musical environment than in a noisy environment in simulated settings. The surgical experience of the team members is negatively correlated with their time gap score, where surgeons with a higher experience score are less affected by noise.. Team resistance to acoustic distraction may lead to novel methods for assessing team skills and fulfill our long-term goal of improving surgical team performance and patient safety. 


\section{Abbreviations}

ANOVA: analysis of variance

CS: Collaborative Suturing

OT: Object Transportation

PANAS-SF: Positive and Negative Affect Schedule

POMS: Profile of Mood States

\section{Declarations}

\section{Ethics approval and consent to participate}

The study protocol was approved by the University of West China Hospital of Sichuan University Research Ethics Board (2019 Approval No. 1071). Informed consent was obtained from all participants prior to data collection. Each participant provided written consent before entering the study.

\section{Consent for publication}

Not applicable.

\section{Availability of data and material}

The datasets used and/or analysed during the current study are available from the corresponding author on reasonable request.

\section{Competing interests}

The authors declares that they have no competing interests.

\section{Funding}

This work was supported by the Chengdu Science and Technology Program Projects [2017-CY02-00024GX].

\section{Authors' contributions}

$\mathrm{YH}, \mathrm{BZ}$, and DP conceptualized the study, YH, LZ, JH, CZ, RX, and CW implemented the experiment, YH and BZ collected and analyzed the data, YH, BZ, and DP drafted the manuscript, LZ, JH, CZ, RX, and CW contributed to revising the manuscript, $\mathrm{YH}$ and $\mathrm{BZ}$ prepared the tables and figures. All authors reviewed the manuscript.

\section{Acknowledgments}


The authors would like to thank all the surgeons who donated their time to participating in this study.

\section{References}

1. Oomens P, Fu VX, Kleinrensink VEE, Kleinrensink GJ, Jeekel J (2020) The Effects of Preferred Music on Laparoscopic Surgical Performance: A Randomized Crossover Study. World J Surg 44:2614-2619

2. Makama JG, Ameh EA, Eguma SA (2010) Music in the operating theatre: opinions of staff and patients of a Nigerian teaching hospital. Afr Health Sci 10:386-389

3. Ullmann Y, Fodor L, Schwarzberg I, Carmi N, Ullmann A, Ramon Y (2008) The sounds of music in the operating room. Injury 39:592-597

4. Bosanquet DC, Glasbey JC, Chavez R (2014) Making music in the operating theatre. BMJ 349:g7436

5. El Boghdady M, Ewalds-Kvist BM (2020) The influence of music on the surgical task performance: A systematic review. Int J Sur 73:101-112

6. Oomens P, Fu VX, Kleinrensink GJ, Jeekel J (2019) The effect of music on simulated surgical performance: a systematic review. Surg Endosc 33:2774-2784

7. Schneider AJ, Biebuyck JF (1990) Music in the operating-room. Lancet 335:1407

8. Fu VX, Oomens P, Kleinrensink VEE, Sleurink KJ, Borst WM, Wessels PE, Lange JF, Kleinrensink GJ, Jeekel $J(2020)$ The effect of preferred music on mental workload and laparoscopic surgical performance in a simulated setting (OPTIMISE): a randomized controlled crossover study. Surg Endosc

9. Wiseman MC (2013) The Mozart effect on task performance in a laparoscopic surgical simulator. Surg Innov 20:444-453

10. Jones MH, West SD, Estell DB (2006) The Mozart effect: Arousal, preference, and spatial performance. Psychol Aesthet Creat Arts S:26-32

11. Mietzsch S, Bergholz R, Boettcher J, Klippgen L, Wenskus J, Reinshagen K, Boettcher M (2020) Classical but Not Rap Music Significantly Improves Transferability and Long-Term Acquisition of Laparoscopic Suturing Skills: A Randomized Controlled Trial. Eur J Pediatr Surg 30:541-547

12. Narayanan A, Gray AR (2018) First, do no harmony: an examination of attitudes to music played in operating theatres. N Z Med J 131:68-74

13. Hawksworth C, Asbury AJ, Millar K (1997) Music in theatre: not so harmonious. A survey of attitudes to music played in the operating theatre. Anaesthesia 52:79-83

14. Way TJ, Long A, Weihing J, Ritchie R, Jones R, Bush M, Shinn JB (2013) Effect of noise on auditory processing in the operating room. J Am Coll Surg 216:933-938

15. Shawagfeh MT, Korsten P, Sawaqed RS, Sweiss NJ (2014) Noise or silence in the operating room? J Am Coll Surg 218:150

16. Yang J, Zheng B, Cai X, Wang Z, Yu H, Cheng Y, Yu X (2020) Effect of Emotional Response on the Performance of a Simulated Laparoscopic Task. Simul Healthc

17. Moris DN, Linos D (2013) Music meets surgery: two sides to the art of "healing". Surg Endosc 27:719723 
18. Conrad C, Konuk Y, Werner P, Cao CG, Warshaw A, Rattner D, Jones DB, Gee D (2010) The effect of defined auditory conditions versus mental loading on the laparoscopic motor skill performance of experts. Surg Endosc 24:1347-1352

19. Gao J, Liu S, Feng Q, Zhang X, Zhang J, Jiang M, Wang L, Zhang Q (2018) Quantitative Evaluations of the Effects of Noise on Mental Workloads Based on Pupil Dilation during Laparoscopic Surgery. Am Surg 84:1951-1956

20. Keller S, Tschan F, Semmer NK, Holzer E, Candinas D, Brink M, Beldi G (2018) Noise in the Operating Room Distracts Members of the Surgical Team. An Observational Study. World J Surg 42:3880-3887

21. Zheng B, Fung E, Fu B, Panton NM, Swanström LL (2015) Surgical team composition differs between laparoscopic and open procedures. Surg Endosc 29:2260-2265

22. Zheng B, Panton ON, Al-Tayeb TA (2012) Operative length independently affected by surgical team size: data from 2 Canadian hospitals. Can J Surg 55:371-376

23. Zheng B, Swanström LL, Meneghetti A, Panton ON, Qayumi AK (2011) Quantifying surgeon's contribution to team effectiveness on a mixed team with a junior surgeon. Surgery 149:761-765

24. Weilenmann S, Schnyder U, Parkinson B, Corda C, von Känel R, Pfaltz MC (2018) Emotion transfer, emotion regulation, and empathy-related processes in physician-patient interactions and their association with physician well-being: a theoretical model. Front Psychiatry 9:389-389

25. Zheng B, Denk PM, Martinec DV, Gatta P, Whiteford MH, Swanström LL (2008) Building an efficient surgical team using a bench model simulation: construct validity of the Legacy Inanimate System for Endoscopic Team Training (LISETT). Surg Endosc 22:930-937

26. Albrecht RR, Ewing SJ (1989) Standardizing the administration of the Profile of Mood States (POMS): development of alternative word lists. J Pers Assess 53:31-39

27. Watson D, Clark LA, Tellegen A (1988) Development and validation of brief measures of positive and negative affect: the PANAS scales. J Pers Soc Psychol 54:1063-1070

28. Derossis AM, Fried GM, Abrahamowicz M, Sigman HH, Barkun JS, Meakins JL (1998) Development of a model for training and evaluation of laparoscopic skills. Am J Surg 175:482-487

29. Zheng B, Taylor MD, Swanström LL (2009) An observational study of surgery-related activities between nurses and surgeons during laparoscopic surgery. Am J Surg 197:497-502

30. Zheng B, Tien G, Atkins SM, Swindells C, Tanin H, Meneghetti A, Qayumi KA, Neely O, Panton M (2011) Surgeon's vigilance in the operating room. Am J Surg 201:673-677

31. Zheng B, Verjee F, Lomax A, MacKenzie CL (2005) Video analysis of endoscopic cutting task performed by one versus two operators. Surg Endosc 19:1388-1395

\section{Figures}

\section{Figure 1}


Experimental setting. Two surgeons were assigned to 2-person teams to perform simulated tasks as follows: the object transportation (top panel) and collaborative suturing tasks (right screen). Please note that participants were wearing headsets that delivered three different acoustic conditions.

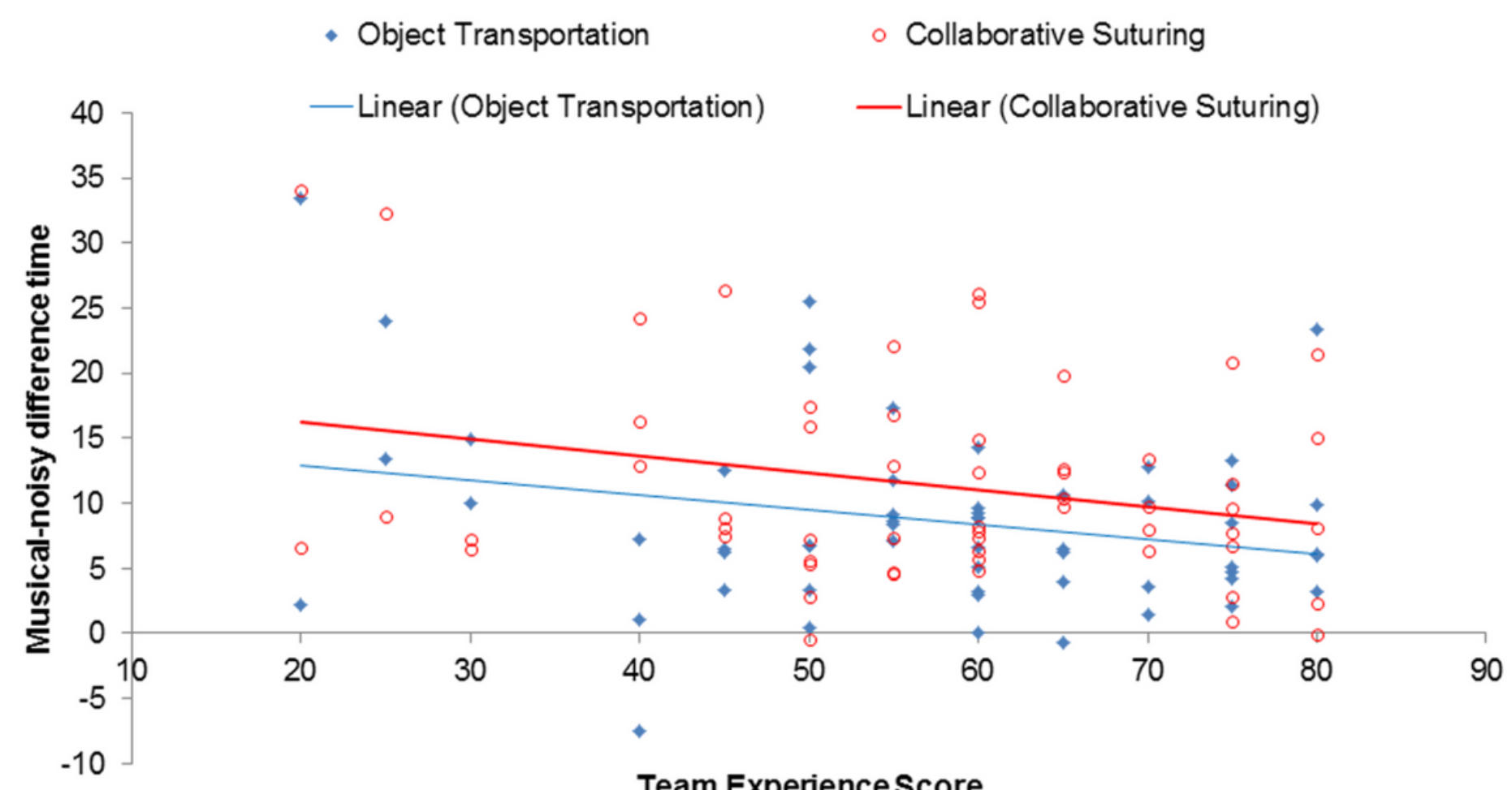

\section{Figure 2}

Scatter plots displaying the correlations between team experience scores and musical-noisy difference time for the object transportation (blue) and collaborative suturing (red) tasks. 